\title{
Los solteros en las ciudades griegas arcaicas y clásicas: tratamiento legal y representaciones*
}

\section{Single Men and Women in Archaic and Classical Greek Cities: Legal Treatment and Representations}

\section{Florence Gherchanoc}

Université Paris Diderot USPC, Francia

Traducción: Estefanía Sottocorno

Universidad de Buenos Aires, Universidad Nacional de Tres de Febrero, Argentina

\section{Resumen}

Este artículo propone una reflexión sobre las formas posibles de presiones social, política y religiosa ejercidas sobre los solteros (aquellas y aquellos que no están casados ni tienen hijos). En relación a las ciudades de Atenas, Esparta y Gortina, así como la ciudad de Magnesia imaginada por Platón, enfoca las modalidades de la regulación de los comportamientos y los discursos relativos a los agamoi. El conjunto lleva a relativizar la idea de un verdadero tratamiento legal de la soltería en las ciudades griegas arcaicas y clásicas.

\section{Résumés}

Cet article propose une réflexion sur les possibles formes de contraintes sociale, politique et religieuse exercées sur les célibataires (celles et ceux qui sont non mariés et sans enfant). Concernant les cités d'Athènes, Sparte et Gortyne ainsi que la cité des Magnètes imaginées par Platon, il analyse, sous cet angle, les modalités de la régulation des comportements et les discours relatifs aux agamoi. L'ensemble conduit à relativiser l'idée d’un véritable traitement légal du célibat dans les cités grecques

Palabras clave

agamos apais

soltero soltería heredera

Mots-clés agamos apais célibataire célibat épiclère

\footnotetext{
* Versión original (en francés) publicada en: Florence Gherchanoc, “ Les célibataires dans les cités grecques archaïques et classiques : traitement légal et représentations ", Cahiers “ Mondes anciens" [En ligne], 10 | 2018, mis en ligne le 13 mars 2018,. URL : http://journals.openedition.org/mondesanciens/1977 - DOI : 10.400o/mondesanciens.1977
} 
1. La cuestión de la soltería y los solteros, en general, ha sido poco atendida por los investigadores, especialmente en el caso de las sociedades griegas antiguas. Las obras relativas a la familia le dedican, a lo sumo, algunas líneas, a menudo relativas a Esparta. Además, las síntesis sobre la soltería o los solteros resultan decepcionantes. V. Abbott (2001 [1999]), Bologne (2004). Se encuentra, no obstante, una noticia " agamiou graphè " de E. Caillemer en el Dictionnaire des antiquités grecques et romaines (DA, p. 130).

2. Cf. Aristóteles, Política, I, 3, 2, 1253b9-11. V. sobre el matrimonio griego, Vérilhac y Vial 1998.

3. Por contraste con otras relaciones que pueden ser consideradas gamos, como las que los hombres mantienen con heteras o concubinas: cf. [Demóstenes], LIX. Contra Nerea, 122

4. Cf. [Aristóteles], Constitución de los Atenienses, LVI, 6-7.
En el mundo griego antiguo, el soltero, "aquel que no está casado", pertenece a la amplia categoría de los agamoi ${ }^{1}$. Respecto de los humanos, este grupo comprende a aquellas y aquellos que no han alcanzado todavía la edad del matrimonio (en Gortina, antes de los 12 años para las muchachas; en la Atenas clásica, antes de los 13-14 años para las herederas; quizás en torno a los 30 años para los muchachos; un poco más tarde en Esparta, alrededor de los 18 años para las muchachas y de los 35 para los hombres), aquellas y aquellos que son viudas / viudos y no se han vuelto a casar y los solteros. Estos últimos son aquellos que, al menos especialmente en el caso de los hombres, rechazan voluntariamente el estatuto de matrimonio tal como lo define, por ejemplo, Aristóteles, como el hecho de sunoikein (convivir) conforme a las leyes de la ciudad ${ }^{2}$. En efecto, las hijas de ciudadanos tienen, desde este punto de vista, un margen de libertad extremadamente reducido, si no inexistente, siendo el matrimonio su telos o realización. Sin embargo, si el matrimonio es el destino de las muchachas, lo es también, en principio, de los muchachos, como atestigua, al menos desde el punto de vista de las representaciones y a su manera la historia de Hipólito, que prefiere al gamos una castidad absoluta, asociada a una forma de piedad excesiva hacia Artemisa. Como se lamenta Afrodita, "se niega al

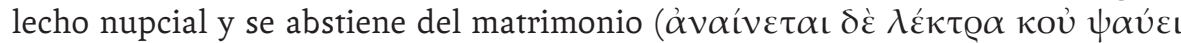

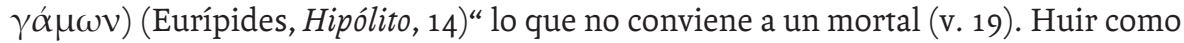
él lo hace de la ralea de las mujeres es ajeno a las normas y, destino trágico, por eso muere, ingresando en la categoría de los paides aôroi (V. Vérilhac 1978-1982). En todos los casos, el matrimonio es lo propio de los mortales, asociado a su condición, según canta ya Hesíodo en la Teogonía y Los trabajos y los días en el siglo VIII a. C. Así, ¿en qué medida la soltería que puede entenderse y definirse como rechazo voluntario del matrimonio kata nomous, conforme a las leyes, reconocido pues como legítimo ${ }^{3}$, ligado a menudo a la ausencia de descendencia legítima, es aceptado y/o constituye un objeto de debate sobre el cual se interviene, por ejemplo legislando, en las ciudades griegas? Estas, en efecto, en general, velan por la continuidad de los oikoi, sus cultos, los honores debidos a los muertos, la buena y justa devolución de los bienes y, por ende, la perpetuación del cuerpo cívico. Asimismo, la ley se preocupa por las muchachas herederas (epicleras) y los hombres adultos no casados, aportando soluciones legislativas y jurídicas, o incluso rituales, diferenciada, como atestiguan los ejemplos mejor o peor documentados de Atenas y Esparta, y adicionalmente de Gortina, que se podrán comparar con las sanciones proclamadas por Platón contra los agamoi, especialmente en la ciudad de Magnesia. Estos casos permiten reflexionar acerca de la presión social, política y religiosa dirigida contra los solteros y analizar, desde esta perspectiva, las modalidades de la regulación de los comportamientos. Me preguntaré pues por las presiones ejercidas por las ciudades sobre los agamoi y sobre los discursos relativos a los solteros. El conjunto lleva a relativizar la idea de un verdadero tratamiento legal de la soltería en las ciudades griegas arcaicas y clásicas.

En Atenas, al menos en la época clásica, la ciudad, a través del arconte-rey, garantiza la buena transmisión de los bienes a las herederas ${ }^{4}$. La ley se preocupa de su matrimonio, impidiendo que permanezcan solteras, agamos, no casadas, sin hijos. En particular, existe un riesgo si la muchacha pertenece a un oikos pobre, porque los bienes a los que está vinculada son menos atractivos:

Cuando una epiclera pertenece a la clase de los thetes, si el pariente más cercano rechaza casarse con ella, deberá otorgarle una dote de 5000, de 300 o de 150 dracmas, según pertenezca a clase de los pentacosiomedimnos, de los caballeros o de los zeugitas, sin contar los bienes personales de la epiclera [...] Si las hijas son muchas, un solo pariente no se verá obligado a ocuparse de más de una: ellas recibirán la dote o se casarán con el siguiente pariente más cercano. Si esto no fuera posible, el arconte obligará al pariente más cercano a desposarla él mismo 
o a dotar a la muchacha. Si el arconte no lo obliga, deberá pagar mil dracmas dedicadas a Hera. Los infractores serán denunciados al arconte por cualquier ciudadano que lo desee ([Demóstenes], XLIII, Contra Macartato, 54).

La heredera debe imperativamente ser entregada en matrimonio al pariente más cercano en orden de sucesión o dotada por éste. La ley designa así a quien detenta la autoridad legal sobre ella, " por defecto " para entregarla en matrimonio5. Hera, como divinidad de las uniones legítimas y del matrimonio ${ }^{6}$, es garante del procedimiento, ejerciendo presión religiosa sobre el magistrado que se abstuviera de aplicar la ley. Aquí está en juego la producción de herederos legítimos (gnêsioi) y de futuros ciudadanos, así como la necesidad de alimentar a la epiclera, siguiendo un principio similar al de la gêrotrophia, la obligación de alimentar a los parientes ancianos, un seguro impuesto por la naturaleza y por la ley?

Como en Atenas, donde Solón es conocido por sus leyes sobre el matrimonio, en Esparta, la ciudad ha establecido procedimientos judiciales provistos de penas que apuntan, entre otras cosas, a sostener por coerción el matrimonio de los más pobres y los agamoi. Al respecto, el caso de las hijas de Lisandro, el famoso general (ss. V- IV a.C.), es interesante:

Tras su muerte, Lisandro fue homenajeado profusamente; los pretendientes de sus hijas, que se habían retractado cuando se descubrió a su muerte cuán pobre era, fueron castigados con una multa por obsequiado para abandonarlo luego, cuando los acontecimientos mostraron su justicia y cualidades morales. 7. Existían en Esparta, aparentemente, castigos para quienes no se casaban, quienes se casaban tarde y

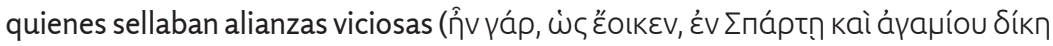

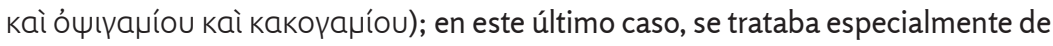
gente que se aliaba a familias ricas, en lugar de buscar personas virtuosas de su entorno (Plutarco, Lisandro, XXX, 6-7).

La ciudad protege a las herederas pobres a través de la ley y de una acción "privada", buscando volver imposible su soltería, al tiempo que se preocupa por la ausencia de matrimonio o por los malos matrimonios ${ }^{8}$. Las cuestiones centrales siguen siendo en Lacedemonia la reproducción a través del matrimonio, en particular en un contexto de baja natalidad registrada a partir del siglo $\mathrm{V}$ a.C., y la mala circulación-transmisión de los bienes a causa de la concentración de la riqueza (V. Hodkinson, 1989 y 2000; Bresson, 1990).

Finalmente en Gortina, la ley evoca igualmente las reglas relativas al matrimonio de la patrôoque: la hija heredera que no tiene hijos puede ser soltera, viuda o divorciada (el código no reglamente el caso de la patrôoque casada). Si es soltera y no ha sido "dada", debe casarse con quien tenga el derecho; puede, no obstante, rechazar la unión a condición de entregar al epiballon la mitad del (excluyendo la casa compartida) y casarse con otro miembro de la tribu (VII, 52-VIII, 7) ${ }^{9}$. En ausencia de un beneficiario de tal derecho, "ella conservará todos los bienes y se casará con quien desee dentro de la tribu “ (VIII, 8). Y “ si nadie de la tribu quiere casarse con ella, los parientes de la muchacha patrôoque dirán en la tribu: “¿Nadie quiere casarse con ella?" Si nadie se presenta para casarse con ella, el matrimonio debe tener lugar treinta días después de la declaración de los parientes, si no la muchacha se casará con quien pueda " (VIII, 13). Los diferentes casos contemplados apuntan a no dar lugar a un grupo de epicleras solteras, porque la buena transmisión de los bienes paternos está en juego, pero probablemente también el futuro de la ciudad, a través de la factura de ciudadanos y la subsistencia de las muchachas no casadas.
5. V. Sebillotte Cuchet 2017, p. 73-76. Cf. [Demóstenes], XLVI. Contra Esteban II, 18.

6. Sobre Hera, en particular cuando tiene por epiklesis teleia, v. Pirenne Delforge y Pironti 2016, c. II.

7. Cf. por ej. [Demóstenes], XLVI. Contra Esteban II, 20: "Si la epiclera tiene un hijo que supera la edad de la pubertad por más de dos años, será propietario de los bienes y proverá de alimentos a su madre “. Este último aspecto relativo a la alimentación de la epiclera - aquí, en el caso de la madre por el hijo heredero de sus bienes- por su kurios aparece ens un registro trágico, en 420 a. C.: Edipo, cuando asume su fin inminente, se dirige a Creonte para que éste se ocupe sus "pobres y miserables" hijas; le pide que las case, hecho que asocia a no dejarlas sin alimento: "no dejes a las hijas de tu sangre vagar sin esposo, mendigando el pan" (Sófocles, Edipo rey, v. 1505-1506. Manifiesta una cierta inquietud de los padres por sus hijas, desprotegidas en las situaciones precarias, en mayor medida que los hijos: "No te preocupes por mis hijos, Creonte. Ellos son hombes: donde vayan, no les faltará el pan" (v. 14591461). Sobre la gêrotrophia, v. De Schutter 1991; Leão 2011; Damet 2012, p. 217-219; Damet 2015.

8. De hecho, la ciudad vela por todas las epicleras. Cf. Heródoto, $\mathrm{VI}, 57,4$ : son los reyes quienes determinan en el marco del derecho (dikazein) “a quién corresponde hacerse cargo, si su padre no la ha comprometido" y designan a tal efecto al pariente más cercano; Aristóteles, Política, II, 9, 1270a26-29: “está permitido entregar la epiclera a quien se desee y, si uno muere sin haberlo dispuesto, el ejecutor testamentario (kleronomos) la entrega a quien él decida". V. Scheid-Tissinier 2018.

9. Cf. Code Gortyne (Nomima II, p. 376), VI 52-VIII, 7; v. Lajeunesse, 2015, § 45-47. 
10. Este telos específicamente femenino es ya el de las muchachas en la epopeya, fuera del marco de la ciudad, como lo manifiesta Nausicaa, pro tou gamou, que teme permanecer "muchacha" (parthenos) [Cf. Homero, Odisea, VI, 33], admês, parthenos no domesticada, sin yugo, sin amo; v. Brulé 2016, p. 47. En el imaginario griego es también el de la heroína Atalanta, que se debe plegar a la ley de Afrodita a través del matrimonio; cf., por ejemplo, Apolodoro, Biblioteca, III, 9, 2. En el mundo de los dioses, sólo tres divinidades, aunque son divinidades, escapan a los erga gamoio ou "labores del himeneo

“. Según reza el Himno homérico a Afrodita I, 6-29: “ [...] hay tres corazones que ella [Aphrodite] no puede persuadir ni seducir -y en principio, la hija de Zeus, portadora de la égida, Atenea de los ojos glaucos [...]: ama las guerras [...] y ocuparse de trabajos nobles [...]

Tampoco puede doblegar nunca la sonriente Afrodita bajo las leyes del deseo (Év Фı dora Artemisa de las flechas de oro

[...] Tampoco la virgen venerada se complace con los trabajos de Afrodita -Hestia-. [...] En lugar de un regalo de bodas (ávì yáuoı), Zeus padre le otorgó un bello privi-

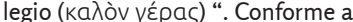
la voluntad del Crónida, las diosas Atenea, Artemisa y Hestia son también ajenas a los tranajos de Afrodita; Cf. Homere, Ilíada, V, 429.

V. Breitenberger 2007. El rechazo de todas las relaciones sexuales, la

ausencia de matrimonio (agamos) e hijos (apaidos) constituyen su timê (honor). En el mismo sentido, de acuerdo con Ateneo, XIV, 617a, Cloto asigna a Atenea "una virginidad sin matrimonio y

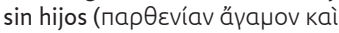
ănaı' ')". También aquí la cuestión del matrimonio se vincula a la de la maternidad y descendencia.

11. Plutarco, Moralia 493e (Sobre el amor de la progenie, 2).

12. Sobre el adulterio, v. entre otros, DA, s. v. Adulterium (t. 1, p. $84-85$, G. Humbert y E.

Caillemer); Schmitt Pantel 1981;

Cohen 1984; Hoffmann 1990 ; Carey 1995 ; Kapparis 1996.
Ahora bien, el tema de la soltería de las hijas de ciudadanos es escasamente evocada, como si su destino fuera " natural" y su porvenir se encontrara asegurado. Éstas deben ser entregas en matrimonio legítimo, en vistas de la reproducción y el cumplimiento de su destino de mujeres ${ }^{10}$. Sin embargo, no se ejerce coerción desde el ámbito del derecho sobre un padre que se negara a casar a su hija. En cambio, las epicleras que deben transmitir el patrimonio paterno a sus hijos y que deben ser alimentadas son " objetos " de transacciones matrimoniales cuyo legislador es responsable como garante de la continuidad de los oikoi y de la ciudad, como protector de los bienes y de las personas.

Los hombres adultos que permanecieran solteros parecen ser especialmente considerados por estas medidas legislativas. En efecto y de acuerdo con Plutarco:

En lo que concierne a las uniones (пعрì toùৎ үáuouৎ), observa cuán grande es la conformidad con la naturaleza entre los animales (tò katà థúoıv). En principio, no esperan las leyes sobre la soltería ni el matrimonio tardío, como los conciudadanos

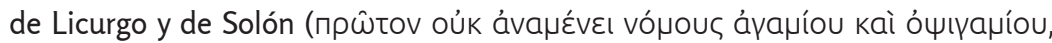

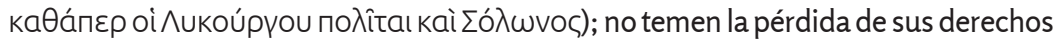

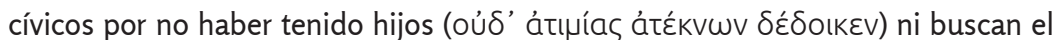
privilegio de los tres hijos, como hacen muchos romanos se casan y se reproducen, no para tener herederos, sino para poder heredar. Luego, el macho no se une a la hembra todo el tiempo, porque no persigue el placer, sino la generación y procrea-

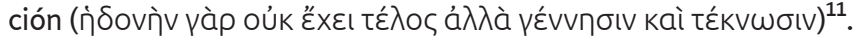

Si seguimos al moralista de los siglos I-II d.C., los dos grandes legisladores arcaicos de Esparta y Atenas, aunque el primero fuese mítico, habrían dado a sus ciudades leyes que sancionaban a los agamoi a través de la atimia - y esto, en vistas de la generación y de la procreación de una descendencia legítima, objetivos de la institución del matrimonio, contrariamente a los amoríos considerados infértiles y fundados exclusivamente en la búsqueda del placer erótico. Asimismo, los procedimientos judiciales conducirán al control de los agamoi et de los ateknoi, acciones de la justicia pública (graphai) que serán comunes a todos los pueblos, siguiendo a Pollux (VIII, 40), mientras que las dikai sobre los matrimonios tardíos y los malos matrimonios (dikê opsigamiou ; dikêkakogamiou) serán propias de los lacedemonios (III, 48).

Estos dispositivos jurídicos deben vincularse con el establecimiento de leyes fundamentales de las ciudades, que generalmente prestan atención a la regulación de las uniones heterosexuales, del matrimonio o del adulterio ${ }^{12}$; y en este contexto, las leyes dan testimonio de una voluntad de regular la factura (generación y procreación) de herederos y de ciudadanos que tiene como corolario el establecimiento de una filiación clara. Como señala Ateneo, a propósito de las leyes "civilizadoras" atribuidas a uno de los primeros reyes míticos de Atenas:

En Atenas, fue Cécrope el primero en unir a una mujer con un hombre; con anterioridad, no había restricciones en relación a estas uniones, que tenían lugar en completa promiscuidad... con anterioridad, los padres eran legión, nadie podía

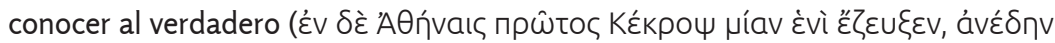

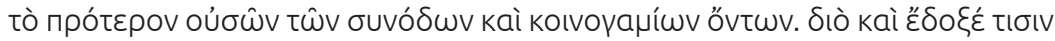

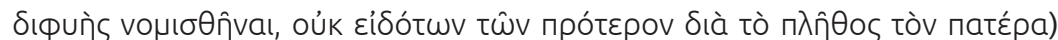
(Ateneo, XIII, 555d).

Cécrope habría terminado también con la koinogamia, una síntesis posible entre la poligamia y la poliandria, y convertido en un vínculo manifiesto el nexo con el padre, la filiación, instaurando la eugeneia. 
Pero, ¿qué sabemos precisamente de la aplicación de estas leyes que apuntan a la factura simultánea de un heredero y de un padre ${ }^{13}$, así como del lugar y las representaciones de los hombres solteros en Atenas y Esparta durante los períodos arcaico y clásico?

En Atenas, algunos alegatos del siglo IV a. C. aluden a la ausencia de matrimonio en el caso de un hombre adulto, estado que sirve como argumento retórico, sea en un contexto familiar, para recuperar una herencia, sea en un marco político, para salvar el prestigio de un hombre público. Así, en el Contra Leocares de Demóstenes, un discurso que no es anterior a los años $330 \mathrm{a}$. C., el conflicto se relaciona con el derecho de sucesión, dado que el último beneficiario, Arquiades, había muerto soltero y apaidos, sin hijos legítimos:

Continuemos. Arquiades no se ha casado (oúk દ́үájel); Midilides, su hermano, sí: era el abuelo de mi padre18. El patrimonio permaneció indiviso; cada uno de ellos tenía de qué vivir, Midilides se quedó en la ciudad y Arquiades vivía en Salamina. Poco tiempo después, mientras que Midilides, el abuelo de mi padre, se encontraba en el extranjero, Arquiades de enfermó; murió en ausencia de su hermano, sin haberse casado jamás (äyajoc): la prueba es que hay un lutróforo sobre su tumba ${ }^{14}$.

El litigante, pregonero en el Pireo, representa a su padre, Aristodemos, nieto por parte de madre de Midilides, hermano del difunto. Para éste, como pariente más cercano (suggenês) de Arquiades, reclama la herencia, discutiendo adopciones póstumas, justificadas por la ausencia de matrimonio y de una descendencia legítima directa:

Para probar que hemos dicho la verdad en cuanto al tema de las adopciones y el

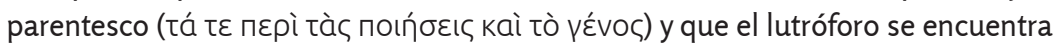
sobre la tumba de Arquiades, queremos leeros este testimonio [...] (Ibid., 30).

La ausencia de matrimonio es una simple constatación, no un juicio de valor. El lutróforo señala el estatuto de agamos del difunto y debería explicitar la situación del titular del derecho' ${ }^{15}$.

En cambio, en un discurso datado en 340 a. C., consagrado a un conflicto relativo también a una herencia, la falta de matrimonio legítima y descendencia es utilizada como argumento discriminatorio:

Y en verdad, a él se lo cuestiona por no haber aceptado el arbitraje de nuestros

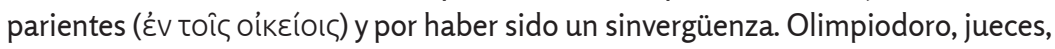

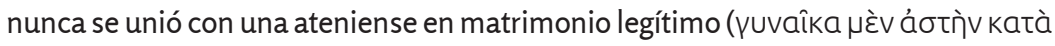

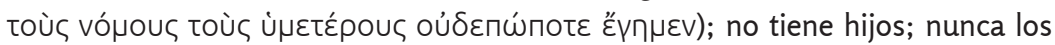

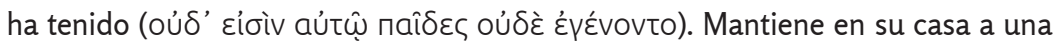
cortesana que ha rescatado, que es precisamente nuestra ruina y que lo vuelve cada vez más loco (Demóstenes, XLVIII. Contra Olimpiodoro, 53).

El hecho de no estar casado con una astê, una hija de ciudadano, kata nomous, conforme a las leyes atenienses, sirve como argumento para desacreditar al adversario que ha captado toda la herencia y no ha respetado el acuerdo de división y de bienes y posterior transmisión a un hijo legítimo. Olimpiodoro, poco confiable, lo es en efecto por no haber contraído unión legítima, prefiriendo amoríos efímeros e infértiles con una hetera. Ni marido, ni padre de hijos legítimos para heredarlo y preservar de ese modo la continuidad del oikos, así como de la ciudad, a través de la producción de herederos y de futuros ciudadanos, sería entonces un mal ciudadano.
13. Sobre la factura del ciudadano, v. Bonnard 2003.

14. Demóstenes, XLIV. Contra Leocares, 17-18. Cf. ibid.1 et 29

15. Sobre el lutróforo como sêma funerario de los solteros, v. Mösch-Klingele 1999, p. 273-275; Mösch-Klingele 2006, p. 3-34 et 117 121; Mösch-Klingele 2010, p. 54-55; Alexandridou 2014, p. 25-26 ey2930. Cf. Pollux, VIII, 66; Hesychios,

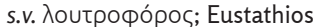
ad. II. 28.141 (= 1293, 6-8). 
16. Sobre la legitimidad de los matrimonios y los nacimientos, v. Gherchanoc 2012, p. 107-124 y 127-139.

17. Cf. Esquines, III. Contra Ctesifonte, 159.

18. V. Storey 1989; Velho 2002; Brulé 2005.

19. En este orden de ideas, según [Aristóteles], Athénaion Politeia, IV, 2, en un pasaje sobre Dracón, el legislador ateniense del siglo VIII a. C., y la primera constitución (politeia), se dice que se eligen los "estrategas y los hiparcas entre aquellos que tenían un patrimonio de al menos cien minas, libre de toda carga, e hijos legítimos, nacidos de una mujer legítima y de más de diez años de edad (kaì naî́ac

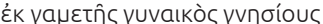

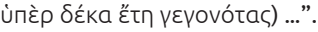
El texto menciona el criterio de edad de los niños. En cambio, en el decreto de Temístocles para los trierarcas, donde se encuentra una fórmula comparable, el criterio de edad enfoca a los padres y no a los hijos: "que los estrategas, a partir de mañana, designan docientos trierarcas, uno por nave, entre aquellos que tengan casa y tierra en Atenas, padres de hijos legítimos, que tengan menos de cincuenta años y que se repartan

las naves entre ellos" (Meiggs y Lewis 1988, $n^{\circ} 23$, p. 18-22; Bertrand 1992, p. 46-47). V. Brocks 2006, p. 8.

20. Cf. Esquines, III. Contra Ctesifonte, 77; Plutarco,

Demóstenes, XXII, 3; Moralia 847b (Vida de los diez oradores).

21. Cf. Ateneo, XIII, 592e-f.
Ejemplo raro, la soltería, entendida como ausencia de matrimonio legítimo, sirve precisamente como argumento en un contexto judicial privado, en el sentido de no político. Con todo, el problema aquí es, sin duda, menos la soltería como tal que el hecho de no contar con descendencia legítima, fruto de una unión legítima. ${ }^{16}$

En un marco político, se movilizan argumentos comparables para perjudicar a un adversario. Se trata ahora de medir justamente la articulación entre ausencia de herederos legítimos y la agamia. El proceso iniciado por Dinarco contra Demóstenes, en 324 a. C., en el momento del caso de Hárpalo, el tesorero de Alejandro, es revelador al respecto:

Que las leyes prescriben al orador y al estratega que pretenden ganar la confianza

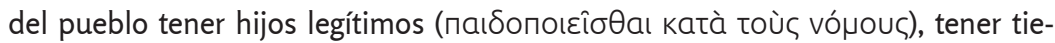
rras al interior de las fronteras y no reclamar el derecho de guiar al pueblo sino a condición de presentar todas las garantías requeridas, que hayas vendido la tierra de tus ancestros, que, sin tener hijos, te atribuyes de manera ilegal pronunciando

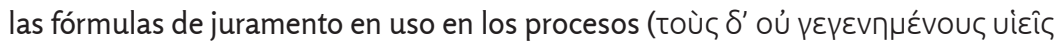

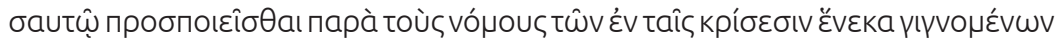
ŏ los raangos. 72. Atenienses, ¿a qué creéis que se debe la prosperidad o decadencia de las ciudades? Exclusivamente, veréis, a sus consejeros y sus jefes. Mirad la ciudad de los tebanos: fue ésa una gran ciudad. ¿Cuándo? ¿Bajo la égida de qué jefes y estrategas? Todos nuestros antecesores, sobre cuyos dichos me basaré, reconocen que en la época 73. en que Pelópidas conducía el batallón sagrado y los generales eran Epaminondas y los compañeros de ambos: fue entonces cuando los tebanos vencieron en Leuctra, cuando invadieron la región de Lacedemonia, hasta entonces considera inexpugnable, que conocieron numerosas proezas brillantes, restablecieron Mesene luego de 400 años y dieron autonomía a los arcadios: gozaban entonces de una reputación universal (Dinarco, I. Contra Demóstenes, 71).

Como estrategia, el orador, adversario de Demóstenes, destaca los elementos relevantes de los terrenos familiar y político que deberían encolerizar a los jueces: por una parte, la paidopoiêsis conforme a la ley de 451, reactivada en 403 a. C., y la enktêsis, la factura de hijos legítimos y el vínculo a la tierra cívica, que garantizan la continuidad de la ciudad; por otra parte, la cobardía o la lipotaxia ${ }^{17}$ que comprometen la defensa del territorio, de las instituciones, de los santuarios y de los oikoi, y son contrarias a la andreia, valor característico del ciudadano ${ }^{18}$.

La paternidad es presentada como una obligación de los oradores y los estrategas que mostrarían así su entrega a la ciudad ${ }^{19}$. La teknopoiêsis sería una suerte de servicio público. Es especialmente relevante la producción de hijos legítimos, antes que de hijas, porque Demóstenes tuvo una hija, muerta en 336 a. $C^{20}$. Además, sobre este punto, Esquines recordaba ya, en 343 a. C., que Afóbeto, su hermano menor, "embajador ante el rey de los persas", contrariamente a Demóstenes:

Cumplió de manera digna de la ciudad la misión que le asignasteis; encargado de la administración de las finanzas, ha gestionado vuestros recursos de manera irreprochable; los hijos que tiene son fruto de una unión legítima (пєпаıбопоıпнह́voৎ katà toù vónouc), no ha sido como tú, meter a su mujer en la cama de Cnosion [...] (Esquines, II. Sobre la embajada infiel, 149).

Demóstenes sería pues un esposo mediocre y un mal ciudadano: no ha tenido hijos,

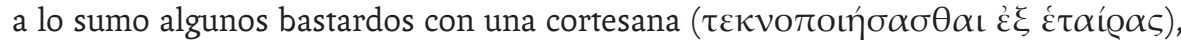
los mismos que ha llevado ante el tribunal, en ocasión de su Discurso sobre el Oro, para obtener la compasión de los jueces ${ }^{21}$; además, transformando a su mujer en 
esposa adúltera, no la ha preservado como productora de una descendencia legítima. Su akolasia (licencia) justifica su no paternidad kata nomous, dado que la teknopoiêsis no se volcó a la factura de hijos legítimos y, por ende, futuros ciudadanos. La mala reputación de Demóstenes, funcional a Dinarco, es anterior al proceso que le inicia.

Sin embargo, en boca del logógrafo, en particular, el argumento de la teknopoiêsis resulta del todo falaz. Por una parte, Epaminondas, el estratega en cuestión, muere soltero y sin hijos, a diferencia de Demóstenes, incluso cuando al morir, según dice, se jactó de dejar a la posteridad "dos hijas [inmortales], la victoria de Leuctra y la de Mantinea"22. Por otra parte, la ley ateniense permite a un ciudadano desprovisto de herederos legítimos adquirirlos a través de la adopción ${ }^{23}$.

En todos los casos, no más en Atenas que en Tebas, suponiendo incluso que exista una forma de reconvención, la ausencia de descendencia legítima o paternidad serían condenadas por la ley ${ }^{24}$. Además, contrariamente a lo que sugiere Plutarco ${ }^{25}$, la existencia de un nomos soloniano forzando la unión de los solteros parece dudosa. $\mathrm{Al}$ respecto, Estobeo (siglo V d. C.) transmite una tradición diferente de la del moralista: "Cuando le propusieron [a Solón] establecer una ley contra los que no se casaban, respondió: la mujer es una carga (phortion) difícil" ${ }^{26}$. De hecho, es probable que la mención de Plutarco evidencia una sobreinterpretación de las leyes sobre el matrimonio y la dote atribuidas por la tradición al legislador ateniense. Porque, en efecto, como escribe en la Vida de Solón:

[el legislador] no quería que el matrimonio se convirtiera en lucro u ocasión de provecho; la vida entre un hombre y una mujer debía tener como fin la procreación,

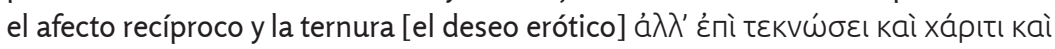

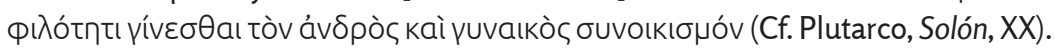

Como en Esparta, Solón habría legislado, inquieto por las estrategias matrimoniales practicadas para concentrar riquezas. De este modo, habría además destacado que la cohabitación (sunoikismos) entre un hombre y una mujer, es decir el matrimonio legítimo, tenía como fin la teknôsis (la factura de hijos) que favorecida por la charis y la philotês, indispensables para la mixis de los cuerpos. La cuestión de la soltería, como ausencia de matrimonio legítimo, se plantea de modo implícito a través de la teknopoiêsis. Por lo demás, Tucídides se demora en la evocación de los atenienses orgullosos de su libertad en materia de epitêdeumata (tipo de vida/costumbres), en tiempos de Pericles, al comienzo de la guerra del Peloponeso, dado que esta particularidad los distinguía justamente de los Lacedemonios ${ }^{27}$. Esto no responde a una coerción social y política relativa a los solteros. En efecto, si, como en otras poleis preocupadas por su futuro, la ciudad legisla sobre el matrimonio legítimo, es poco probable que la ley en Atenas, haya ejercido coerción sobre los solteros para que sellaran una unión considerada legítima. En general, no se estigmatiza a los agamoi, salvo en los litigios donde se manifiesta la mala fe del orador, con el objetivo de influenciar a la opinión pública, sacando provecho de topoi sobre las características del buen ciudadano, a la vez buen marido, buen padre, buen hijo y dedicado a la ciudad; contrariamente al caso de Esparta, no sufren atimia ni censura ni vergüenza por la práctica de un ritual particular. En efecto, respecto de la ciudad de los lacedemonios, las fuentes se hacen eco de un trato específico para los solteros. La intervención del grupo sería más conspicua, verosímilmente a causa de las restricciones impuestas por la oliganthropia y quizás de una inserción más importante de los individuos en la ciudad.

En Esparta, la ley sobre los solteros, atribuida a Licurgo, pertenece efectivamente al grupo de las leyes fundamentales de la ciudad, en particular a aquellas que se ocupan del matrimonio ${ }^{28}$. Por una parte, el legislador "establece que el matrimonio tendría
22. Cf. Diodoro de Sicilia, XV, 87, 6; Cornelio Nepote, Epaminondas, $\mathrm{XV}, 10,1-2$, a propósito de la batalla de Leuctra que sobrevivirá al general tras su muerte. 23. Sobre la adopción en Atenas, v. Rubinstein 1993. 24. V. Liddel 2007, p. 222-227. 25. Plutarco, Moralia 493e (Sobre el amor de la progenie, 2), mencionado anteriormente en la nota 16.

26. Estobeo, Anthologii, vol. IV, p. 521 (ed. O. Hense, Weidmann, Berlin, 1974).

27. Cf. Tucídides, II, 37, 2-3.

28. Cf. Plutarco, Moralia 493e (Sobre el amor de la progenie, 2). Cf. igualmente Aristón en Estobeo, vol. IV, p. 497 (ed. O. Hense). 
29. Jenofonte, Constitución de los Lacedemonios, I, 6.

30. Plutarco, Licurgo, XV, 1-3. Cf., también Plutarco, Moralia 227 (Apotegmas laconios 14): “ Excluyendo a los solteros de las Gimnopedias y vinculando a la soltería un carácter infamante, pretendía tener poder sobre la ge-

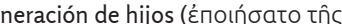
паıбопоıía)); los privó, además, de los honores y consideraciones que los jóvenes deben a sus mayores. Nadie impugnó el designio dirigido un día a Dercílidas, que era un estratega de exposición pública: un cierto hombre joven no se levantó para cederle su sitio:

"No has tenido hijos que un día puedan cereme el sitio a mí. “

31. Cf. supra Plutarco, Lisandro, XXX, 7; Pollux, VIII, 40 y 48.

32. V. Gherchanoc 2018, en prensa.

33. V. Paradiso 1996, p. 116-118; sobre esta fiesta, Richer 2012, p. 390-394; igualmente Meritt 1931

34. Estos se oponen precisamente a los cantos y peanes de los coros de jóvenes desnudos ejecutados durante la fiesta de las Gimnopedias: cf. Pausanias,

III, 11, 9, a propósito de los coros de efebos en honor de Apolo;

cf. Ateneo, XIV, 631b-c; Anecdota

Graeca, I, p. 32, 1. 18-20 (ed.

Bekker), s. v. Gimnopaidia; Suda, S. v. Lycourgos (Suda, ed. A. Adler, Stuttgart, 1971 [1928-1938]) sobre las danzas / coros / ejercicios desnudos (sin clámide) de paides / efebos. Estas sanciones son entonces comparables a las críticas

(psogoi) formuladas contra los cobardes (cf. Plutarco, Licurgo, XXI, 2), contra los que mantienen relaciones homosexuales (cf. Plutarco, Moralia, 237c [Apotegmas laconios]) similares a los cantos de los ilotas.

35. Cf. Platón, Leyes, I, 633c. lugar en el apogeo de la fuerza física, considerando que esto sería propicio para la

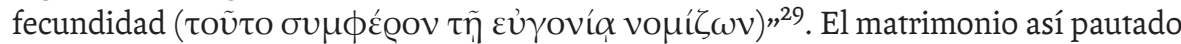
debía favorizar la eugonia, una buena y feliz fecundidad, lo que compromete necesariamente a la soltería entendida como ausencia de gamos. Por otra parte, los agamoi son afectados por la atimia, el deshonor:

Licurgo adjudicó, además, un carácter infamante a la soltería (átıníav

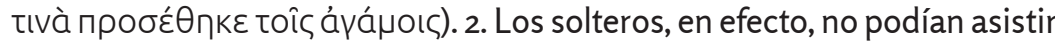
al espectáculo de las Gimnopedias y, en invierno, los arcontes los

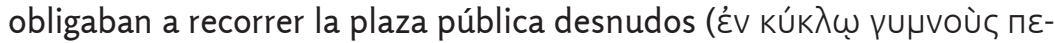
plḯvaı tìv áyopáv) mientras cantaban una canción compuesta contra ellos y decían que se los había castigado justamente por desobedecer las

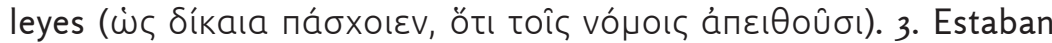

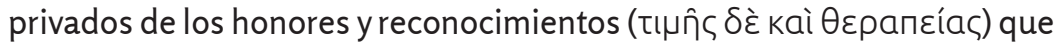
los jóvenes consagraban a sus mayores. Así, nadie condenó el gesto que un joven dedicó un día a Dercílidas, que era no obstante un estratega

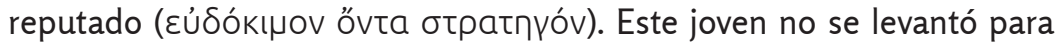
cederle el sitio y le dijo: "Tú no tienes hijos que alguna vez puedan cederme el sitio a mí “30.

Está pues en juego la continuidad de los oikoi y especialmente de la ciudad ante la falta de ciudadanos. En Esparta, el matrimonio se impone por acciones de justicia (dikêagamiou ${ }^{31}$ y humillaciones comparables a los castigos infamantes que golpean a los adúlteros y los cobardes -marcas de deshonor (atimia) que asumen, entre otras, la forma de un ritual de escarnio ${ }^{32}$.

Estos rituales estigmatizan a los agamoi, a la vez que evocan las normas. Así, en verano, los solteros son excluidos de la celebración de las Gimnopedias, una fiesta en honor de Apolo y Artemisa que se desarrolla en el ágora ${ }^{33}$. En invierno, en cambio, en este mismo lugar, se encuentran y corren desnudos en círculo, a la vista de todos, cantando reproches ${ }^{34}$. El sistema opone dos estaciones -unos, los mejores, los jóvenes que encarnan el porvenir prometedor de la comunidad, deben soportar el calor estival ${ }^{35}$, los otros, el frío riguroso del invierno-, dos formas de la desnudez, una atlética y valorada, la otra degradante, y dos tipos de palabras cantadas, de una lado peanes, del otro acusaciones.

Los solteros en Esparta sufren pues una degradación social, religiosa y política que se manifestaría mediante la prohibición de participar en la celebración de una de las fiestas cívicas más importantes, mediante el castigo corporal específico e igualmente mediante el no respeto del principio de ancianidad. Con todo, el soltero Dercílidas, que ha estado activo en Asia Menor entre 399-397 a. C. y ha obtenido numerosas victorias contra los persas, conserva su cargo de estratega y sigue siendo un jefe militar reconocido y estimado. No pierde todos sus derechos políticos. Contradice parcialmente las expectativas relativas a su género, por no haberse casado con el objetivo de dar niños a la ciudad.

Clearco de Solos (ss. IV-1/2 III a. C.), citado por Ateneo, menciona una variante del proceso infamante contra los solteros:

En Lacedemonia, [...], en ocasión de una fiesta, los agamoi eran perseguidos alrededor de un altar por mujeres casadas, que les daban latigazos para que abandonaran la hybris de su falta, que sintieran deseo y se casaran mientras estuvieran todavía en

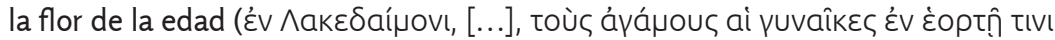

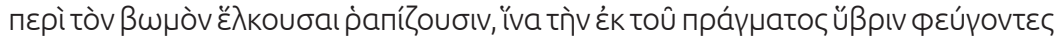

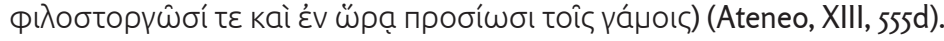


El ritual funciona en este caso como una iniciación al matrimonio, apunta al retorno a una sexualidad regulada. Los solteros pueden escapar a la infamia de su estado mediante el látigo -característico de los castigos destinados a los niños, quienes no son ciudadanos cabales, y los ilotas, los anti-ciudadanos-y nuevamente el movimiento circular ${ }^{36}$. Las mujeres, en calidad de esposas, evocan la norma cívica como en otras ocasiones, en Esparta, lo hacen las madres en relación a sus hijos combatientes ${ }^{37}$.

Cualquiera sea el ritual, va acompañado de una forma de publicidad voluntaria. Se hace un espectáculo de la vergüenza. Asimismo, el ritual debe conducir al matrimonio, porque es el destino de la ciudad lo que está en juego y sobre el cual pesa una amenaza. La atimia es parcial y reversible.

Además, existirían procedimientos alternativos, uno para poner fin a la soltería, otro para producir futuros ciudadanos.

34. Los matrimonios colectivos serían de este modo, al menos hacia el fin del siglo $\mathrm{V}$ a.C., una solución adoptada por la ciudad de Esparta para luchar contra la agamia, particularmente de un sector de la población:

En Lacedemonia, todas las muchachas (пâoaı....ai kópaı) eran encerradas en un sitio oscuro, y junto con ellas los muchachos que no estaban casados

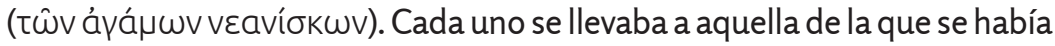
apoderado, sin dote. Fue así que Lisandro terminó recibiendo una multa, porque había abandonada a la muchacha que encontró primero para llevarse a otra más bonita ${ }^{38}$.

La anécdota, transmitida por Hermipo, un autor del siglo III a.C., se refiere a Lisandro; precede los relatos, ya citados, consagrados a la fustigación de los agamoi y a la eugeneia instaurada por Cécrope en Atenas. El texto, crítico en relación al navarca, remite también a otras tradiciones relativas al matrimonio espartano, como las que transmite Plutarco, donde la oscuridad y el desconocimiento mutuo son fundamentales ${ }^{39}$ y donde la elección de la esposa no se funda en la belleza o, dicho de otro modo, en la capacidad de la numphê de producir hijos bellos ${ }^{40}$.

Estos matrimonios afectan, además, a los agamoi o a partidos poco interesantes, como los mothakes, y las hijas sin dote, esto es, individuos de menor valor social y económico, a los que el matrimonio colectivo podría valorizar en algún punto ${ }^{41}$.

Los procesos llevados a cabo en Esparta contra los agamoi mediante la ley y las dikai, así como también mediante los rituales específicos ejercen una forma de presión a la vez política, social y religiosa que se explica, entre otras cosas, por la oliganthropia. Ahora bien, esta presión debe ser relativizada respecto de la libertad de elección de los individuos y, más aún, la existencia de una solución "extrema" propuesta a los ciudadanos agamoi como alternativa al matrimonio legítimo. En efecto, según afirma Jenofonte, en un texto fechado en 387 a. C.:

...inversamente, si alguien no quisiera vivir con una mujer, pero quisiera tener hijos que pudieran ser tenidos en cuenta, Licurgo estableció que fuera legítimo que él tuviera hijos de la mujer que viera provista de lindos hijos y de alcurnia además, siempre que lograra persuadir a su poseedor (દi ઠ

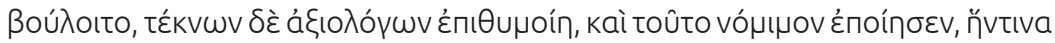

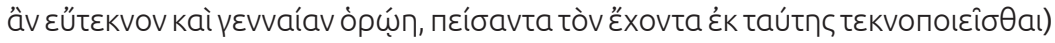
(Jenofonte, Constitución de los Lacedemonios, I).
36. Para otro ejemplo de los lazos entre el movimiento ritual en círculos y la vuelta a la normalidad en Esparta, respecto de los hombres que mantienen relaciones homosexuales, cf. Plutarco, Moralia, 237c (Apotegmas laconios 7-9). 37. V. especialmente Delattre 2012.

38. Hermipo en Ateneo, XIII, $555 \mathrm{C}$. V. los comentarios de Bommelaer (1981, p. 58), que, sobre Aristóteles, Política, II, 9, 7; 13-15, 1269b, duda sobre la existencia de matrimonios, sin la elección de allegados y familiares. La concentración de propiedades prohibiría pensarlo; v. Cartledge 1981, p. 96 y 98 . Quant à Meillier (1984), interpreta esta "costumbre" como un encuentro iniciático hierogámico, sin lazos con el matrimonio social. Sobre el vínculo con las prácticas eugenésicas espartanas, v. Damet 2018.

39. Cf. Plutarco, Licurgo, XV, 1-7.

40. Ahora bien, Lisandro elige precisamente una esposa adecuada por su belleza a la imagen de la de un jefe político y militar o de alguien que aspirara a convertirse en rey de Esparta. Su comportamiento es elitista, la belleza de la esposa es un elemento de distinción y valor. La elección es probablemente tan importante como para compensar la eventual pobreza o un estatuto de mothax y sería un factor de promoción social y política. V. Gherchanoc 2016, p. 87-88.

41. Sobre la hipótesis de matrimonios socialmente no reconocidos, $\mathrm{v}$. Pirenne-Delforge 1994, p. 205-207. Sobre la pobreza de Lisandro, cf. Plutarco, Agis y Cleómenes, VIII, 1; Filarco en Ateneo, VI, 271e-f (FGrH $\left.81 \mathrm{~F}_{43}\right)$; Eliano, Historias varias, XII, 43. Sobre los mothakes, v. entre otros Lotze 1962; Bommelaer 1981, p. 36-38; Hodkinson 200o, p. $198,355-356$ et 415; Ducat 2006, p. 128-129, 134-135 y 150-154. 
42. Cf. también Polibio, Historias, XII, 6b, 8 y Nicolás de Damasco,

$\mathrm{F} 144,6$ que asocian la poliandria a una forma de paternidad colectiva. Sobre la poliandria, v. Perentidis 2006 y Damet 2018.

43. Por comparación, respecto de Atenas, Sócrates puede explicar a su hijo: "Sin duda, no te imaginas que es exclusivamente por los placeres de Afrodita que los hombres generar hijos (паıбопоเєібӨa), dado que las calles y las casas están llenas de medios para satisfacerlos; pero se nos ve considerar qué mujeres nos darán los hijos

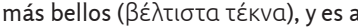
éstas que nos unimos para cumplir nuestras expectativas" (Jenofonte,

Memorables, II, 2, 4 La visión propuesta del matrimonio es aristocrática y eugenésica. Los medios difieren pero el objectivo es el mismo que en Esparta. Cf. supra nota 16 a propósito del placer opuesto a la generación y la procreación. Las proposiciones de Platón, en las Leyes, son similares. Cf. infra.

44. Cf. Platón, Leyes, 783d-e: “ La esposa y el esposo deben considerar dar a la ciudad los más bellos y mejores hijos

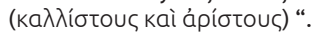

La poliandria constituye así una opción posible para aquel que rechaza la cohabitación o el matrimonio en vistas de la producción de buenos / bellos ciudadanos ${ }^{42}$. A falta de una esposa bella, el agamos en cuestión puede elegir una "madre portadora" de calidad, si su kurios acepta. La paidopoiêsis y la euteknia se encuentran en el centro del dispositivo ${ }^{43}$.

Estas preocupaciones relativas a la producción o factura de bellos y numerosos hijos son igualmente las de Platón. Reflexionando sobre este aspecto, en relación al mejor modelo de organización política para la ciudad de Magnesia, se inspira ampliamente en el sistema lacedemonio y propone leyes intervencionistas contra los solteros. El objetivo sigue siendo engendrar los mejores niños:

En alguna familia, pues, en la ocasión que fuere, cuando un hombre de al menos veinticinco años, gracias a las observaciones que hubiera hecho y de las que hubiera sido testigo, cree encontrar a alguien que le agrada y resulta conveniente para una unión destinada a darle hijos, que se case, siempre antes de cumplir treinta y cinco años, pero que escuche primero cómo debe buscar la mujer conveniente y dotada

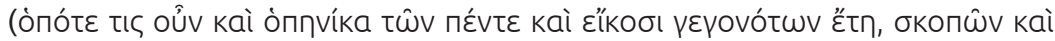

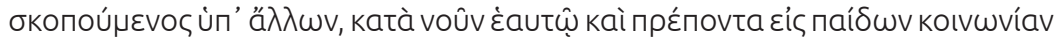

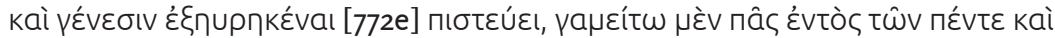

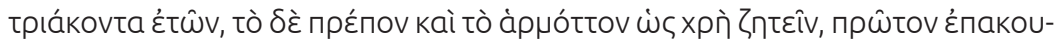

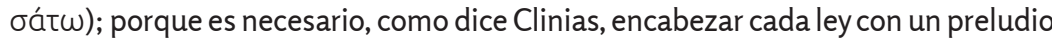
apropiado (Platón, Leyes, VI, 772d-e).

La coerción al matrimonio en vistas de la continuidad de la ciudad afecta al grupo de los ciudadanos entre veinticinco y treinta y cinco años, un criterio etario que, como en Esparta, debe favorecer también la producción de bellos hijos ${ }^{44}$. Prevé, sin embargo, que la esposa elegida sea "conveniente y dotada", es decir, destacada entre las demás por su comportamiento y aspecto físico.

En cambio:

Si alguien no obedece libremente, sino que permanece extranjero y antisocial dentro

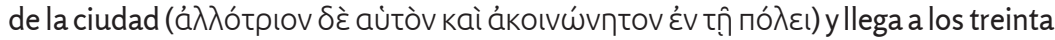
y cinco años sin tomar mujer, recibirá cada año una multa: cien dracmas para la clase más alta, setenta para la segunda, sesenta para la tercera y treinta para la cuarta. Este dinero será consagrado a Hera. Si se omite la contribución anual, se deberá pagar luego el doble, que será recaudado por el tutor de la diosa; si éste no logra reunir el dinero, será él mismo deudor de esa suma y, en ocasión de la rendición de cuentas, cada ciudadano será interrogado al respecto. Éstas serán las multas financieras para

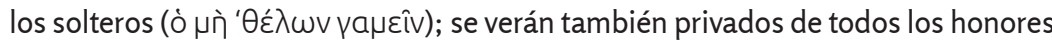

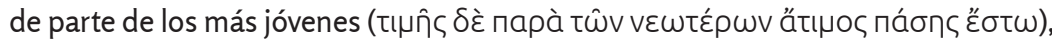
que tampoco les obedecerán voluntariamente; si se proponen castigar a alguien, todo ciudadano deberá ponerse de parte de la víctima y si alguno no lo hace, será

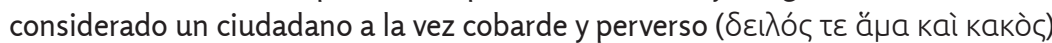
(Platón, Leyes, VI, 774 a-c).

Aquel que se niega a casarse en la edad pautada, es castigado con una multa anual imprescriptible y proporcional a su fortuna, consagrada a Hera, garante del matrimonio legítimo; este deshonor se expresa, además, como en Esparta, por el descrédito del principio de ancianidad por parte de los más jóvenes que ejercen de este modo una forma de presión social y "moral" sobre los agamoi. En esta ciudad, el matrimonio y la teknopoiêsis aparecen como un servicio cívico. Constituyen deberes del ciudadano, que actúa contra la ciudad si no los cumple, transformándose en extranjero por su rechazo a participar de la koinônia. Tal comportamiento conforma 
una anti/a-sociabilidad, por no decir incivilidad. Así, la idea es ejercer una presión social, económica, moral y religiosa para obligar a los solteros a casarse en interés y al servicio de la ciudad.

Las ciudades griegas se preocupan del matrimonio en vistas de la generación, esencial para su supervivencia. Legislan así para definir las modalidades de la legitimidad del gamos, de interesan por la transferencia de la riqueza considerando la dote, el destino de las muchachas -en particular de las epicleras-y de los futuros hijos de esta unión, protegiendo y garantizando sus derechos. Es precisamente en este contexto que hay que situar el tratamiento "legal" de la soltería a relativizar de manera diferenciada según se trate de hombres o mujeres, respecto de la ausencia de filiación legítima, primordial para los griegos.

En el caso de las epicleras solteras, la ley interviene cuando no hay un kurios, para garantizar la buena transmisión de los bienes paternos, luchar contra estrategias matrimoniales que buscan concentrar riquezas y asegurar la subsistencia.

En el caso de los hombres adultos, la soltería es raramente afectada por una sanción judicial relacionada con la atimia parcial y una multa, siendo Esparta una excepción notoria que se explicaría por una situación demográfica preocupante. La falta de matrimonio kata nomous y/o sobre todo de paternidad, en las ciudades donde ser un buen esposo, un buen padre y un buen hijo es un deber del ciudadano y constituye un topos esencial de la ideología cívica, es sin embargo ocasionalmente condenada por la opinión a un grado más o menos elevado; puede servir de argumento contra un adversario político, por ejemplos, en los procesos atenienses del siglo IV, puede conducir a humillaciones en Esparta. Los discursos asocian generalmente estas dos actitudes, ser agamos y apais, que caracterizan, en el mito escenificado por Platón en el Banquete, al individuo muy viril, exponente del hombre dedicado a perseguir lo que desea (arrenos):

Una vez alcanzada la edad viril, aman a los muchachos; respecto del matrimonio y la paternidad [factura de niños], manifiestan una indiferencia natural (үánouৎ kaì

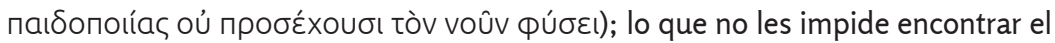

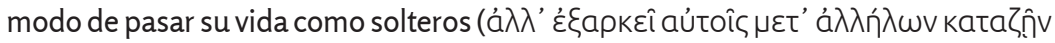
áyájoıc). En una palabra, amar a los muchachos, querer a los amantes, éstas son las cualidades de tales hombres, ya que se vinculan con lo que les es familiar (ázì

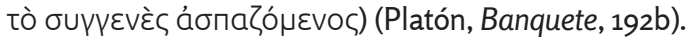

El soltero es un hombre viril que ama y se siente atraído por sus semejantes, rechazando así la heterosexualidad y la paternidad. Ahora bien, precisamente en el mundo de las ciudades griegas de los períodos arcaico y clásico, la ley y los rituales evocan la norma y destacan la importancia acordada a la continuidad de la ciudad y la factura de hijos legítimos, lo que supone una unión legítima conforme a la ley. Sin embargo, a pesar de los valores políticos, sociales, económicos y religiosos vinculados al matrimonio y la paternidad, el intervencionismo en Atenas en relación a los hombres adultos solteros es hipotético. En cuanto a Esparta, las diferentes tradiciones relativas a la intervención judicial y ritual contra los agamoi manifiestan una preocupación más importante en una ciudad que sufre oliganthropia, lo que explicaría la fuerza de la presión social, religiosa, moral y política que se ejercía allí. Sin embargo, el rasgo dominante sigue siendo el de una cierta libertad individual. Además, las leyes se ocupan menos de la soltería como tal que de la ausencia de un descendiente heredero legítimo y futuro ciudadano, a la cual las ciudades pueden aportar soluciones -poliandria en Esparta, leyes sobre las adopciones, etc.- que no son necesariamente vinculantes. 


\section{Q Bibliografía}

》 Abbott, E. (2001 [1999]). Histoire universelle de la chasteté et du célibat. Montréal. [A History of Celibacy]. Cambridge.

" Alexandridou, A. (2014). "De l'eau pour les défunts. Les hydries à décor peint en contexte funéraire attique de l'âge du Fer à l'époque archaïque”, Pallas 94, p. 17-38. DOI : 10.4000/pallas.1530

" Bertrand, J.-M. (texto establecido y traducido por) (1992). Inscriptions historiques grecques. Paris.

» Bologne, J.-C. (2004). Histoire du célibat et des célibataires. Paris.

» Bommelaer, J.-F. (1981). Lysandre de Sparte. Histoire et traditions. Athènes-Paris.

» Bonnard, J.-B. (2003). "Un aspect positif de la puissance paternelle: la fabrication du citoyen”, Mètis N.S. 1, p. 69-93.

"Breitenberger, B. (2007). Aphrodite and Eros. The Development of Erotic Mythology in Early Greek Poetry and Cult. New York-Londres.

"Brocks, R. (2006). “How To Be a Citizen in Ancient Greece”, Journal of Classics Teaching 8, p. 5-9.

" Bresson, A. (1990). “Le cercle des oikeioi à Sparte”, Mélanges P. Lévêque 5, p. 69-104.

»Brulé, P. (2005). "Les codes du genre et les maladies de l'andréia: rencontres entre structure et histoire dans l'Athènes classique", en Bertrand J.-M. ed., La violence dans les mondes grec et romain, Paris, p. 247-267.

» Brulé, P. (2016). “Sur la Dios kourê”, Pallas 100, p. 33-57.

" Carey, C. (1995). "Rape and Adultery in Athenian Law”, CQ 42-2, p. 407-417. DOI: 10.1017/ Sooog838800043482

» Cartledge, P. (1981). “ Spartan Wives: Liberation or Licence? “, CQ N.S. 31, p. 84-109. DOI: 10.1017/Sooog838800021091

»Cohen, D. (1984). “ The Athenian Law of Adultery “, RIDA 31, p. 147-165.

» DA : Daremberg C., Saglio E. y Pottier E. (1873-1919). Dictionnaire des antiquités grecques et romaines, Paris.

"Damet, A. (2012). La septième porte. Les conflits familiaux dans l'Athènes classique, Paris.

»Damet, A. (2015). “ Le statut des mères dans l'Athènes classique “, dans Gherchanoc F. (ed.), Mères grecques, Cahiers "Mondes anciens " 6, on line. URL : http://mondesanciens. revues.org/1379; DOI : 10.400o/mondesanciens.1379.

» Damet, A. (2018). “ Le bon grain et l'ivraie “, en Damet A. y Armani S. ed., Les politiques familiales dans les mondes antiques, Cahiers "Mondes anciens " 10, on line. URL : http:// journals.openedition.org/mondesanciens/2007 ; DOI : 10.400o/mondesanciens.2007

»Delattre, C. (2012). “ Voix de Lacédémoniennes. Injonction et identité de genre dans les paroles de femmes spartiates “, en Valette E. ed., Femmes de paroles. Voix énonciatives et pragmatique des formes de discours, Cahiers "Mondes Anciens" 3, on line. URL: http:// mondesanciens.revues.org/744; DOI : 10.400o/mondesanciens.744

»De Schutter, X. (1991). “ Piété et impiété filiales en Grèce “, Kernos 4, p. 219-243.

»Ducat, J. (2006). Spartan Education. Youth and Society in the Classical Period, Swansea. 
» Gherchanoc, F. (2012). L'oikos en fête. Célébrations familiales et sociabilité en Grèce ancienne, Paris.

»Gherchanoc, F. (2016). Concours de beauté et beautés du corps en Grèce ancienne, Bordeaux.

» Gherchanoc, F. (2018). “ Déshonneurs corporels et vestimentaires en Grèce ancienne “, en Badel, C. y Fernoux, H. dir., Honneur et dignité dans le monde antique. Actes du colloque des 3-4 avril 2014, Université Rennes 2, Rennes, en prensa.

» Harrison, A. R. W. (1968). The Law of Athens, I. The Familiy and Property, Oxford.

» Hodkinson, S. (1989). “ Inheritance, Marriage and Demography: Perspectives upon the Success and Decline of Classical Sparta “, en Powell A. ed., Classical Sparta: Techniques behind her Success, Londres, p. 79-121.

» Hodkinson, S. (2000). Property and Wealth in Classical Sparta, Londres.

» Hoffmann, G. (1990). Le châtiment des amants dans la Grèce classique, Paris.

» Kapparis, K. (1996). “ Humiliating the Adulterer: the Law and the Practice in Classical Athens “, RIDA 43, p. 63-77.

» Lajeunesse, M. (2015). “ La mère dans le Code de Gortyne : reconnue juridiquement, mais pas autonome pour autant “, dans Gherchanoc F. (dir.), Mères grecques, Cahiers “ Mondes anciens “ 6, on line. URL : http://mondesanciens.revues.org/1367 ; DOI : 10.4000/mondesanciens.1367

» Leão, D. (2011). “ Paidotrophia et gerotrophia dans les lois de Solon “, RD 89-4, p. 457472.

» Liddel, P. (2007). Civic Obligation and individual Liberty in Ancient Athens, Oxford. DOI : 10.1093/acprof:0so/9780199226580.001.0001

» Lotze, D. (1962) : “ MOTHAKES “, Historia 11, p. 427-435.

» Meiggs, R. et Lewis D. (1988). A Selection of Greek Historical Inscriptions, Oxford.

» Meillier, C. (1984). “ Une coutume hiérogamique à Sparte “, REG 97, 1984, p. 381-402. DOI : 10.3406/reg.1984.1397

» Meritt, B. D. (1931). “ The Spartan Gymnopaidia “, CPh 26, p. 70-84. DOI : 10.1086/361309

» Mösch-Klingele, R. (1999). “ Loutra und Loutrophoros im Totenkult. Die literarischen Zeugnisse “, dans Docter R. F. y Moormann E. M. dir., Proceedings of the 15 th International Congress of Classical Archaeology, Amsterdam, July 12-17 1998: classical archaeology towards the third millenium: reflections and perspectives, Amsterdam, p. 273-275.

» Mösch-Klingele, R. (2006). Die „loutrophoros “im Hochzeits- und Begräbnisritual des 5. Jahrhunderts v. Chr. in Athen, Berne.

» Mösch-Klingele, R. (2010). Braur oder Bräurigam. Schwarz - und rotfigurige Lutrophoren als Spiegel gesellschaftligen Veranderungen in Athen, Mayence.

" Nomima II: Van Effenterre H. y Françoise Ruzé F. (1995). Nomima. Recueil d'inscriptions politiques et juridiques de l'archaïsme grec II, [Droit et société], Rome.

» Paradiso, A. (1996). “ Le corps spartiate. Entre mirage et réalité “, Communications 61-1, p. 113-124.

»Perentidis, S. (2006). “ Sur la polyandrie, la parenté et la définition du mariage à Sparte“, en Bresson, A., Masson, M.-P., Perentidis, S., Wilgaux, J. (ed.), Parenté et société dans le monde grec de l'Antiquité à l'âge moderne, Bordeaux, p. 131-152.

» Pirenne-Delforge V. (1994). L'Aphrodite grecque, Kernos suppl. 4, Athènes-Liège. DOI : 
10.4000/books.pulg.1409

» Pirenne-Delforge, V. y Pironti, G. (2016). L'Héra de Zeus, Paris.

» Richer, N. (2012). La religion des Spartiates. Croyances et cultes dans l'Antiquité, Paris.

" Rubinstein, L. (1993). Adoption in IV. Century Athens, Copenhague.

» Scheid-Tissinier, É. (2018). “ L’épiclérat athénien. Essai de mise au point “, en Damet A. y Armani S. ed., Les politiques familiales dans les mondes antiques, Cahiers “ Mondes anciens “10, on line. URL: http://journals.openedition.org/mondesanciens/1998 ; DOI : 10.400o/mondesanciens.1998

» Schmitt Pantel, P. (1981). “ L’âne, l'adultère et la cité “, en Le Goff J. y Schmitt J.-C. ed., Le Charivari, Paris, p. 117-122 retomado en Schmitt Pantel P. (2009). Aithra et Pandora. Femmes, Genre et Cité en Grèce ancienne, Paris, p. 91-98.

» Sebillotte Cuchet, V. (2017). “Familles et société à Athènes à l'époque classique: un éclairage par les études de genre “, Pallas, Hors Série, p. 71-90.

» Storey, I. C. (1989). “ The ‘blameless Shield’ of Kleonymos “, RhM 132, p. 247-261.

»Velho, G. (2002). “ Les déserteurs des armées civiques en Grèce ancienne ou la négation du modèle du soldat-citoyen “, LEC 70, p. 239-256.

» Vérilhac, A.-M. (1978-1982). Paides Aoroi. Poésie funéraire I-Il, Athènes.

» Vérilhac, A.-M. y Vial C. (1998). Le mariage grec: du Vle siècle av. J.-C. à l'époque d'Auguste, BCH suppl. XXXII, Paris. 